\title{
DATING DRY BURN INJURY IN HUMAN PATIENTS BY FLOW CYTOMETRY OF CD4+ AND CD8+ T-CELLS IN THE BLOOD
}

\author{
Fatma M. Elgazzar ${ }^{a}$, Kareem G. Alsharkawy ${ }^{b}$, Rasha A. Elkholy ${ }^{c}$, Heba I. Lashin ${ }^{a}$ \\ ${ }^{a}$ Forensic Medicine and Clinical Toxicology Department, Faculty of Medicine, Tanta \\ University, Tanta, Egypt.

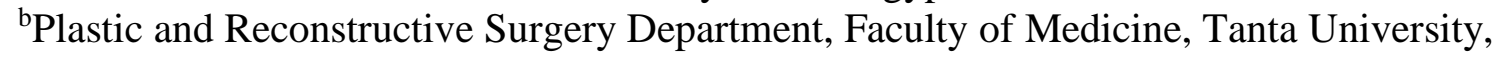 \\ Tanta, Egypt. \\ ${ }^{\mathrm{c} C l i n i c a l}$ Pathology Department, Faculty of Medicine, Tanta University, Tanta, Egypt.
}

Corresponding author: Heba I. Lashin, Forensic Medicine and Clinical Toxicology Department $-6^{\text {th }}$ floor Faculty of Medicine - Tanta University - Medical Campus - El-Gash Street - Tanta - El-Gharbia Govenorate Egypt.

Email: heba.lashen@med.tanta.edu.eg

Telephone number: +201020016903

Submit Date 2020-08-26

Revise Date 2020-12-17

Accept Date 2020-12-22

\begin{abstract}
Introduction: dating burn injury in humans remains a challenging issue in forensic medicine. T-lymphocytes have a fundamental role in the healing process of burn injury. The study aimed to characterize time-dependent changes in t-helper lymphocytes $(\mathrm{cd} 4+)$ and tcytotoxic lymphocytes (cd8+) in human blood following thermal injury and to elucidate their accuracy in dating dry burn injury. Patients and methods: this cross-sectional study included adult patients, admitted with second and /or third-degree dry burn with a total body surface area ranged from $10 \%$ to $50 \%$. Ten eligible patients were recruited independently at the $1 \mathrm{st}$, $3 \mathrm{rd}, 7 \mathrm{th}$, and 15th days following burn injury. Additionally, ten matched healthy subjects served as a control group. Besides the patient's information, blood samples were withdrawn from each participant for flow cytometric analysis of $\mathrm{cd} 4+$ and $\mathrm{cd} 8+\mathrm{t}-$ cells. Results: percentages of cd4+ and cd8+ cells, and cd4+/cd8+ ratio exhibited a significant reduction in burnt patients compared to the control group throughout the first week after-burn. Additionally, there was a significant time-dependent decline between the 1st, 3rd, and 7th days, following the burn. Receiver operating characteristic (roc) analysis for these markers revealed a significant-excellent power of discrimination of burns aged less than 3 days (area under the curves were $\geq 0.9$ ). Conclusion: it could be concluded that cd4+ and cd8+ t-cells in the human blood exhibited time-dependent changes after dry burns. They could help in dating acute dry burns in living humans with great accuracy, whatever the extent of burn injury.
\end{abstract}

Keywords: dating; age; burns; human; $c d+4$ and cd+8; flow cytometry

\section{INTRODUCTION}

Burn is one of the major causes of injury worldwide (Li et al., 2017). In forensic practice, various burn injuries due to exposure to fire, hot liquids, or electricity are frequently encountered. Determining the time of these burn incidents is very essential both in living persons and cadavers (El-Sayed, 2016).

Medicolegal evaluation of burns remains a major concern in the field of clinical forensic medicine. These circumstances include acute burns due to assault or intentional self-inflicted burns for secondary gains. Additionally, burns are commonly encountered in cases of child, elder, or intimate partner abuse (Greenbaum et al., 2006; Nisavic et al., 2017). Moreover, forensic pathologists sometimes face a diagnostic challenge in estimating the time passed since fire. Accurate dating might provide a clue to 
know the survival time of the victim. Besides, it can help in the reconstruction of the crime scene (Li et al., 2020).

Estimating the age of burns based on the naked eye evaluation of morphological changes related to various stages of healing is highly variable ( $\mathbf{L i}$ et al., 2020). Moreover, the recently known scar imaging tools have not been yet valid for forensic purposes (Mukherjee et al., 2017).

The healing process of burns involves the release of numerous cytokines and growth factors as mediators that control and organize various stages of healing (Sorg et al., 2017). The progress in forensic techniques has enabled the evaluation of multiple inflammatory mediators for wound dating purposes through various immunohistochemistry or molecular biology procedures, both in animals and humans (van de Goot et al., 2014; Fronczek et al., 2015).

The currently available research on dating burn injury in humans is scarce. An earlier study has reported an increased p53 expression in the thermal injury of the human skin (Tarran et al., 2004). Another immunohistochemical study of the inflammatory response in biopsy samples of burnt living human subjects. It revealed a tendency for increased neutrophils in samples taken as early as 2 days after the injury, whereas macrophages predominated in burns aged a few days to weeks old. However, the authors reported difficulty in determining the burn age (Tarran et al., 2006). To date, there was no efficient or reliable biomarker for burn dating (Li et al., 2020).

T-lymphocytes have a fundamental role in the healing process of burn injury. They regulate the recruitment of inflammatory cells, inflammatory mediators, and growth factors at the site of thermal injury. Moreover, a proper immune response depends essentially on T-cell (Kim et al., 2017). The role of both T-Helper lymphocytes (CD4+) and TCytotoxic lymphocytes (CD8+) subsets in the healing process of burns including monitoring cytokines secretion has been reported by Cairns et al. (2001).

It has been reported that major burns induce impairment of the immune responses early after injury (Rani and Schwacha, 2017). Such immunosuppressive effect of major burns on T-cell subtypes and its relation to morbidity and mortality has been well established (Girardot et al., 2017).

The reported burn-related T- cells responses could be adopted to determine burn age for medicolegal purposes. Therefore, the present study aimed to characterize time-dependent changes in $\mathrm{CD}+4$ and $\mathrm{CD}+8$ T-cells in the blood following thermal injury. Further, to elucidate the potential role and accuracy of these T-cell subtypes in dating dry burn injury in living humans.

\section{PATIENTS \& METHODS}

\section{Study type, settings, and ethical considerations}

This analytical cross-sectional study was carried out at Burn Unit, Plastic and Reconstructive Surgery Department, Tanta University Hospital. The study was undertaken after approval from the institutional research ethics committee (Approval Code: 32997/03/19), throughout a period from the start of March to the end of June 2019. Informed written consent was taken from the study participants. To maintain the confidentiality of data, a code number was given for every patient.

\section{Eligibility criteria}

Male or female patients, aged 18 years or older, admitted with second and /or third-degree dry burn injuries (at least 1\% deep partial-thickness burn area), of moderate to a severe extent; total body surface area (TBSA) ranged from $10 \%$ to $50 \%$ were recruited. Patients with any comorbidity likely to affect the level of $\mathrm{T}$ lymphocyte subsets as hepatic, renal insufficiency, or any local or systemic septic conditions were excluded.

Ten eligible patients were recruited at 
the 1st, 3rd, 7th, and 15th days following burn injury constituting independent groups from I to IV. They covered the inflammatory (12 hours-2 days) and proliferative (3-14 days) stages of the burn healing process. Additionally, ten matched healthy subjects with no hepatic, renal insufficiency, or any local or systemic septic condition were selected during the study period. They served as a control group.

It has been reported that responses of T-lymphocyte subsets might be related to the extent of burns (Jeschke et al., 2008). This was considered in this study, thus eligible patients with moderate burns (TBSA more than 10\% and less than 30\%) and severe burns (31-50\% TBSA) were equally recruited at each studied time point after burn injury.

\section{Methods}

Patient's information including age, sex, type of burn, TBSA, admission period, history of any comorbidity or septic condition were collected. Additionally, from each participant, two $\mathrm{ml}$ of the peripheral venous blood sample was drawn into a sterile vacutainer containing K3EDTA $(1.2 \mathrm{mg} / \mathrm{ml})$ as an anticoagulant for flow cytometric analysis of $\mathrm{CD}+4$ and CD+8 T-cells.

Flow cytometric analysis: was done using CD 4 FITC, CD 8 PE monoclonal antibodies. These markers were supplied by Becton Dickinson (Heidelberg, Germany). Samples were analyzed by four-color flow cytometry using the Becton Dickinson (BD) FACS Calibur instrument (Becton Dickinson, San Diego, California, USA). The leucocytic count was adjusted to $10^{6}$ cells/tube, fluorochromes conjugated monoclonal antibodies were dispensed into all appropriately labeled tubes (volume of each antibody is determined according to titration which is labeled on each monoclonal bottle). The tubes were vortexed and incubated in the dark at room temperature for $25 \mathrm{~min}$. One $\mathrm{ml}$ of lysing solution was added to the tubes. The tubes were vortexed and incubated for $20 \mathrm{~min}$ in the dark at room temperature. A volume of $0.5 \mathrm{ml}$ of phosphate buffer saline washing solution was added to each tube and mixed thoroughly. The tubes were centrifuged at $2500 \mathrm{rpm}$ for $3 \mathrm{~min}$, and the supernatant was discarded, this step was repeated. Cells were suspended in $300 \mu$ of phosphate buffer saline and were ready for acquisition by the flow cytometer.

For each analysis, 10,000 events were acquired and analyzed using the Cell Quest software; CELL QUEST SOFTWARE (Becton Dickinson, version 3, verify software House Topsham, ME, USA). An acquisition gate was done based on FSC and SS from which lymphocytes were selectively gated for immunophenotyping analysis. Marker expression was recorded as a percentage and absolute count of positive cells (Fig. 1).

\section{Statistical Analysis}

All data were analyzed by SPSS version 22. Categorical data were presented as numbers and percentages and Pearson's Chi-Square test was used to investigate the association between two variables. Concerning continuous data, they were tested for normality by the Shapiro Wilk test. They were normally distributed and were expressed as mean \pm standard deviation and were compared by Independent Student's T- test and OneWay ANOVA according to the number of groups. Following significant One-Way ANOVA results, a post hoc test (Games Howell) was applied to determine the pairwise comparison between the studied groups. Also, Receiver operating characteristic (ROC) curves were constructed to assess the diagnostic performance of the studied markers in the dating burn injury. $\mathrm{P}<0.05$ was considered statistically significant.

\section{RESULTS}

The present study included 40 patients with mixed second- and/or third-degree dry burns. The burn surface area ranged from $10 \%-50 \%$. More than half of them 
$(57.5 \%)$ were females and their mean age was $31.65 \pm 8.95$ years, with nonsignificant differences from the control healthy subjects.

Table (1) shows the relation between the severity of burn according to TBSA and the percentage of CD4+ and CD8+Tlymphocytes in the peripheral blood. The means of CD4+ and CD8+ percentages as well as $\mathrm{CD} 4+/ \mathrm{CD} 8+$ ratio were significantly lower in severe burns compared to moderate ones at each of 1 st, 3rd, and 7th days after burn $(\mathrm{p}<0.05)$. Whereas, in group IV (15th-day after-burn) neither $\mathrm{CD} 4+, \mathrm{CD} 8+$ percentages nor CD4/CD8 ratio showed statistically significant differences ( $p>0.05)$.

Concerning moderate burns, the mean of CD4+percentage was significantly lower at each of the 1st, 3rd, and 7th days after burn compared to the control group $(25.16 \pm 0.45,22.02 \pm 0.44,30.98 \pm 1.61$, and $34.10 \pm 2.45$ respectively, $\mathrm{p}<0.001)$. Additionally, along the first- week afterburn, there was a significant difference in CD4+ percentage between the studied periods. However, the difference between the 7 th and 15th days was not statistically significant $(\mathrm{p}=0.227)$. Likewise, themean $\mathrm{CD} 8+$ percentages and $\mathrm{CD} 4+/ \mathrm{CD} 8+$ ratio was significantly lower at each of the $1 \mathrm{st}$, 3rd, and 7th days after burn compared to the control group with significant differences between the studied periods till the end of the first week (Table 2).

Table (3) demonstrates timedependent responses of CD4+ and CD8+ lymphocytes to severe burns. There was a significant reduction in the mean CD4+percentage 1st day following severe burns compared to the control group $(22.02 \pm 0.44$ and $37.80 \pm 2.28$ respectively, $\mathrm{p}<0.001)$. On the $3 \mathrm{rd}$ day, the reduction continued (mean $=19.38 \pm 0.88$ ) with a significant difference from the control group. On the 7 th day, CD4+cells started to increase but, the mean CD4+percentage $(29.16 \pm 1.35)$ was still significantly lower than the control group. Nevertheless, two weeks after severe burns, the mean
CD4+percentage $(33.94 \pm 2.43)$ was nonsignificantly lower than the control group $(p=0.162)$. Besides, there were significant differences in the mean CD4+ percentages between all the studied periods $(\mathrm{p}<0.001$ between 1st, 3rd, 7th, and 15th days). Correspondingly, the mean CD8+ percentage and the ratio of absolute numbers of $\mathrm{CD} 4+$ and $\mathrm{CD} 8+$ cells displayed similar significant timedependent differences at each of $1 \mathrm{st}, 3 \mathrm{rd}$, 7 th, and 15th days following severe burns $(\mathrm{p}<0.001)$.

To determine the diagnostic performance of each of CD4+, CD8+ percentages, and $\mathrm{CD} 4+/ \mathrm{CD} 8+$ ratio in discriminating the age of burns, ROC curves were applied. For moderate burns, CD4+, CD8+ percentages and CD4+/CD8+ ratio showed a significantexcellent power of discrimination of burns aged less than 3 days $(\mathrm{p}<0.001)$. Moreover, $\mathrm{CD} 4+/ \mathrm{CD} 8+$ ratio displayed the greatest power of discrimination $(\mathrm{AUC}=0.980)$, but with no significant differences from AUCs of CD4+ and CD8+ percentages ( $p>0.05)$. At a cutoff $\leq 0.94$, the $\mathrm{CD} 4+/ \mathrm{CD} 8+$ ratio provided a sensitivity of $80 \%$ and a specificity of $100 \%$ (Table 4 and fig. 2).

As regards severe burns, CD4+, CD8+ percentages and CD4+/CD8+ ratio showed a significant-excellent power of discrimination of burns aged less than 3 days $\quad(p<0.001)$ Moreover, CD4+ percentage showed the best diagnostic value $(\mathrm{AUC}=0.90)$, but with no significant differences from AUCs of CD8+ percentage and $\mathrm{CD} 4+/ \mathrm{CD} 8+$ ratio ( $>0.05)$. The percentage of CD4+ cells had a sensitivity and specificity of $90 \%$ at a cutoff $\leq 22.1$ (Table 5 and fig. 3 ).

\section{DISCUSSION}

This study identified the pattern of CD4+ and CD8+ cells' response to burn injury and their role in determining the burn age. The application of the flow cytometry technique allowed a precise determination of changes in the positively stained mononuclear cells at different time 
points following the injury (Cossarizza et al., 2017).

The present work demonstrated a significant reduction in CD4+ and CD8+ percentages, and $\mathrm{CD} 4 / \mathrm{CD} 8$ ratio in burnt patients compared to the control healthy subjects throughout the first week afterburn. Also, the observed suppression of
CD4+ and CD8+ cells in this study was related to the extent of the burn. As well, both moderate and severe burns expressed a significant time-dependent reduction in $\mathrm{CD} 4+$ and $\mathrm{CD} 8+$ percentages, and CD4/CD8 ratio at the 1 st, $3 \mathrm{rd}$, and 7 th days following the burn.

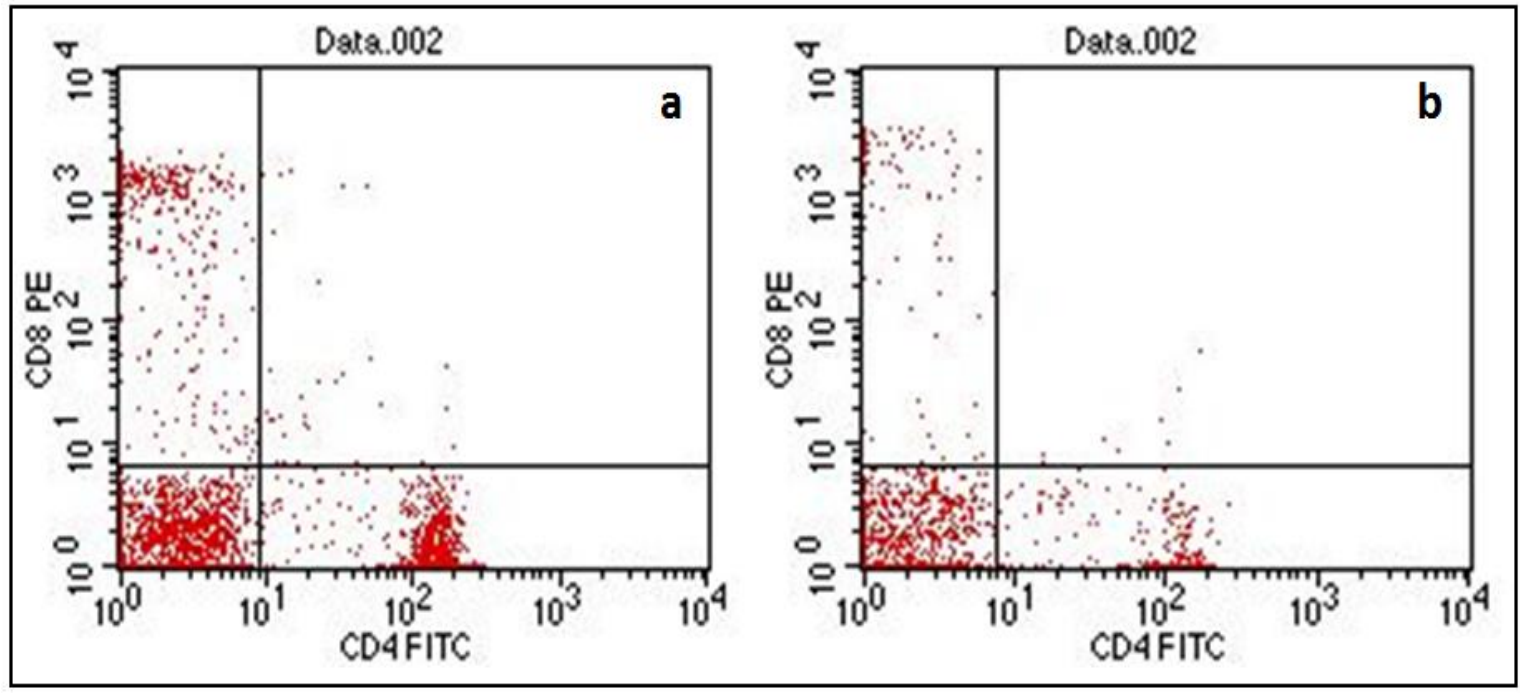

Figure 1: (a) Percentage of positive cells for the 2 subsets CD4+ and CD8+ in healthy control. (b) A decrease in the percentage of positive cells for the 2 subsets CD4+ and CD8+ in burnt patients.

Table (1): Comparison between moderate and severe burns regarding CD4+, CD8+ percentages, and CD4+/CD8+ ratio at each studied time interval

\begin{tabular}{|l|c|c|c|c|c|}
\hline \multirow{2}{*}{} & \multicolumn{2}{c|}{ Patients (n=40) } & \\
\cline { 2 - 5 } & Group I (1 day after burn) (n=10) & P value \\
\hline CD4+\% & Mean \pm SD & $25.16 \pm 0.45$ & $22.02 \pm 0.44$ & 11.1 & $<0.001^{*}$ \\
\hline CD8+\% & Mean \pm SD & $16.0 \pm 1.06$ & $13.98 \pm 0.98$ & 3.12 & $0.014^{*}$ \\
\hline CD4+/CD8+ ratio & Mean \pm SD & $0.94 \pm 0.02$ & $0.89 \pm 0.02$ & 5.0 & $0.001^{*}$ \\
\hline \multicolumn{7}{|c|}{ Group II (3 days after burn) $(\mathbf{n = 1 0})$} \\
\hline CD4+\% & Mean \pm SD & $22.02 \pm 0.44$ & $19.38 \pm 0.88$ & 5.99 & $<0.001^{*}$ \\
\hline CD8+\% & Mean \pm SD & $13.50 \pm 1.12$ & $10.94 \pm 0.98$ & 3.85 & $0.005^{*}$ \\
\hline CD4+/CD8+ ratio & Mean \pm SD & $0.88 \pm 0.02$ & $0.65 \pm 0.11$ & 4.47 & $0.007^{*}$ \\
\hline \multicolumn{7}{|c|}{ Group III (7 days after burn) $(\mathbf{n = 1 0})$} \\
\hline CD4+\% & Mean \pm SD & $30.98 \pm 1.61$ & $29.16 \pm 1.35$ & 3.96 & $0.006^{*}$ \\
\hline CD8+\% & Mean \pm SD & $18.98 \pm 1.55$ & $16.34 \pm 0.70$ & 3.46 & $0.008^{*}$ \\
\hline CD4+/CD8+ ratio & Mean \pm SD & $1.30 \pm 0.16$ & $1.01 \pm 0.05$ & 3.86 & $0.005^{*}$ \\
\hline \multicolumn{7}{|c|}{ Group IV (15 days after burn) $(\mathbf{n}=10)$} \\
\hline CD4+\% & Mean \pm SD & $34.10 \pm 2.45$ & $33.94 \pm 2.43$ & 0.104 & 0.920 \\
\hline CD8+\% & Mean \pm SD & $20.38 \pm 0.88$ & $19.86 \pm 0.73$ & 1.02 & 0.339 \\
\hline CD4+/CD8+ ratio & Mean \pm SD & $1.44 \pm 0.15$ & $1.50 \pm 0.10$ & 0.739 & 0.481 \\
\hline
\end{tabular}

*Significant at $\mathrm{p}<0.05$ 
Table (2): Time-dependent responses of CD4+, CD8+ percentages, and CD4+/CD8+ ratio in moderate burns

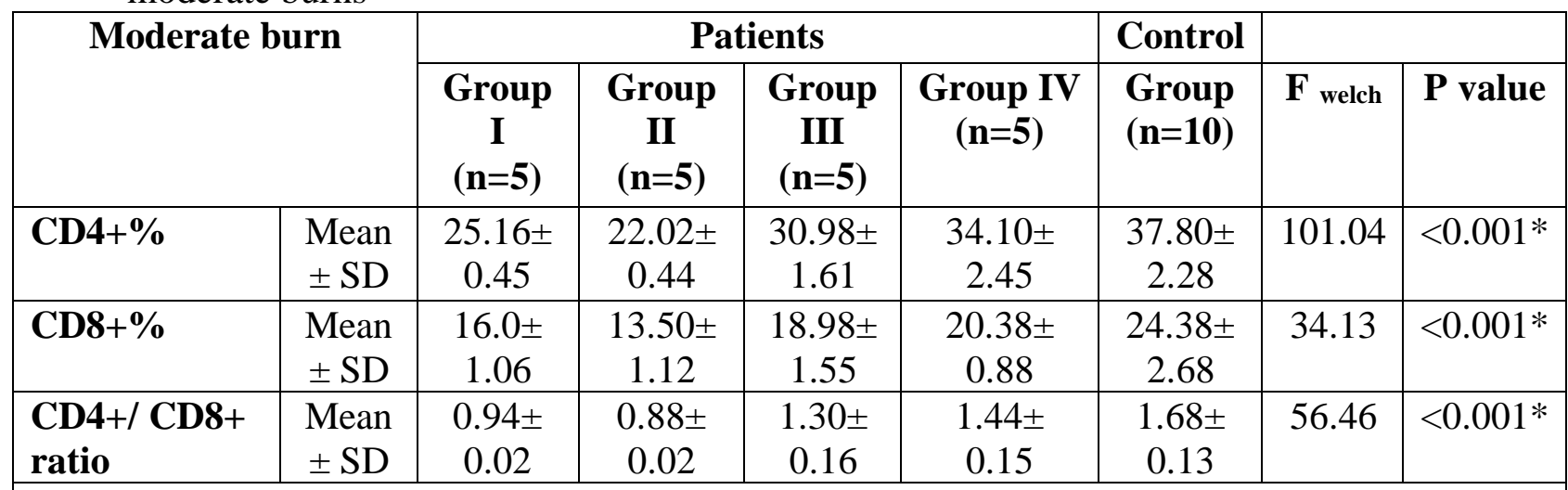

CD4+\%: Post hoc test (Games Howell) revealed significant differences between all groups except group III versus group IV ( $\mathrm{p}=0.227)$, and group IV versus control group $(\mathrm{p}=0.190)$.

CD8+\%: Post hoc test (Games Howell) revealed significant differences between all groups except group III versus group IV ( $\mathrm{p}=0.467)$, and group IV versus control group $(\mathrm{p}=0.117)$.

CD4+/CD8+ ratio: Post hoc test (Games Howell) revealed significant differences between all groups except group III versus group IV ( $\mathrm{p}=0.628)$, and group IV versus control group $(\mathrm{p}=0.145)$.

*Significant at $\mathrm{p}<0.05$

Table 3: Time-dependent responses of CD4+, CD8+ percentages, and CD4+/CD8+ ratio in severe burns

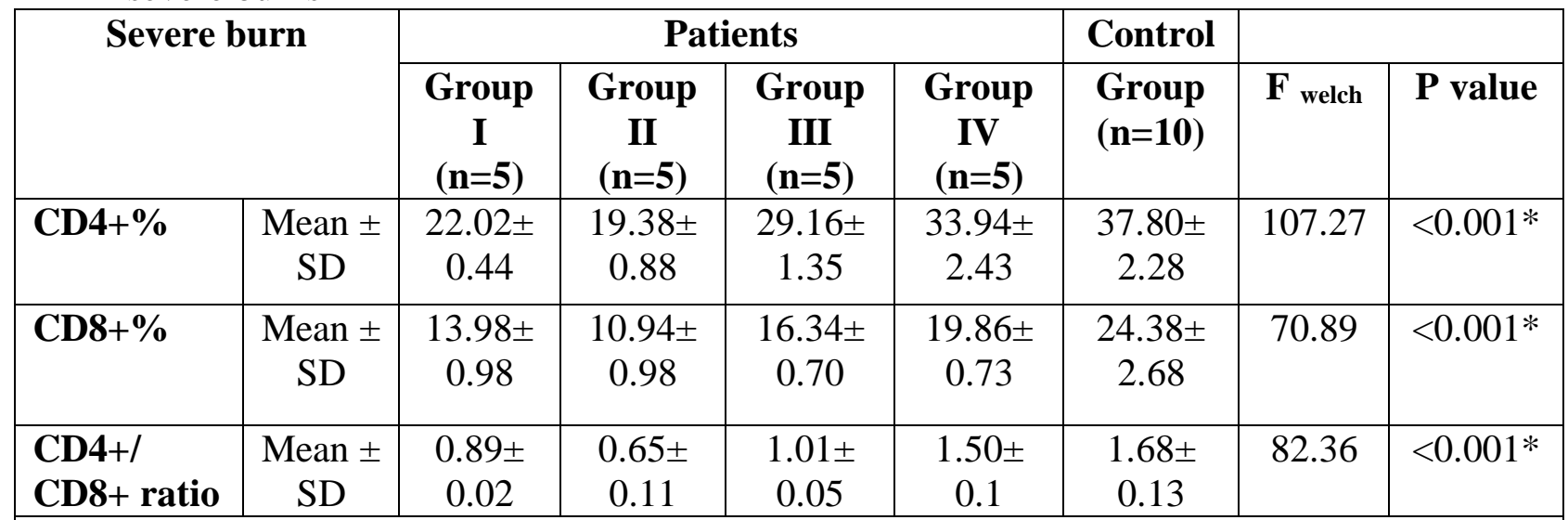

CD4+\%: Post hoc test (Games Howell) revealed significant differences between all groups except group IV versus control group $(\mathrm{p}=0.162)$.

CD8+\%: Post hoc test (Games Howell) revealed significant differences between all groups except group IV versus control group $(\mathrm{p}=0.079)$.

CD4+/CD8+ ratio: Post hoc test (Games Howell) revealed significant differences between all groups except group IV versus control group $(\mathrm{p}=0.201)$.

*Significant at $\mathrm{p}<0.05$ 
Table (4): Diagnostic performance of CD4+, CD8+ percentages, and CD4+/CD8+ ratio of moderate burns aged less than 3 days

\begin{tabular}{|l|c|c|c|c|c|c|}
\hline Moderate burn & Cutoff & Sensitivity\% & Specificity\% & AUC & $95 \%$ CI & P value \\
\hline CD4+\% & $\leq 25.6$ & 90 & 80 & 0.905 & $\begin{array}{c}0.690- \\
0.989\end{array}$ & $<0.001^{*}$ \\
\hline CD8+\% & $\leq 16.0$ & 80 & 100 & 0.975 & $\begin{array}{c}0.789- \\
1.0\end{array}$ & $<0.001^{*}$ \\
\hline $\begin{array}{l}\mathrm{CD} 4+/ \mathrm{CD} 8+ \\
\text { ratio }\end{array}$ & $\leq 0.94$ & 80 & 100 & 0.980 & $\begin{array}{c}0.797- \\
1.0\end{array}$ & $<0.001^{*}$ \\
\hline
\end{tabular}

Comparison of the three ROC curves revealed non -significant differences between AUCs of the studied markers $(\mathrm{p}>0.05)$.

*Significant at $\mathrm{p}<0.05$; AUC: area under the curve; CI: confidence interval

Table (5): Diagnostic performance of CD4+, CD8+ percentages, and CD4+/CD8+ ratio of severe burns aged less than 3 days

\begin{tabular}{|l|c|c|c|c|c|c|}
\hline \multicolumn{1}{|c|}{ Severe burn } & Cutoff & Sensitivity\% & Specificity\% & AUC & $95 \%$ CI & P value \\
\hline CD4+\% & $\leq 22.1$ & 90 & 90 & 0.90 & $0.683-0.988$ & $<0.001 *$ \\
\hline CD8+\% & $\leq 14.9$ & 80 & 90 & 0.890 & $0.670-0.984$ & $<0.001 *$ \\
\hline CD4+/CD8+ ratio & $\leq 0.91$ & 70 & 90 & 0.895 & $0.677-0.986$ & $<0.001 *$ \\
\hline
\end{tabular}

Comparison of the three ROC curves revealed non -significant differences between AUCs of the studied markers $(\mathrm{p}>0.05)$.

*Significant at $\mathrm{p}<0.05$; AUC: area under the curve; CI: confidence interval

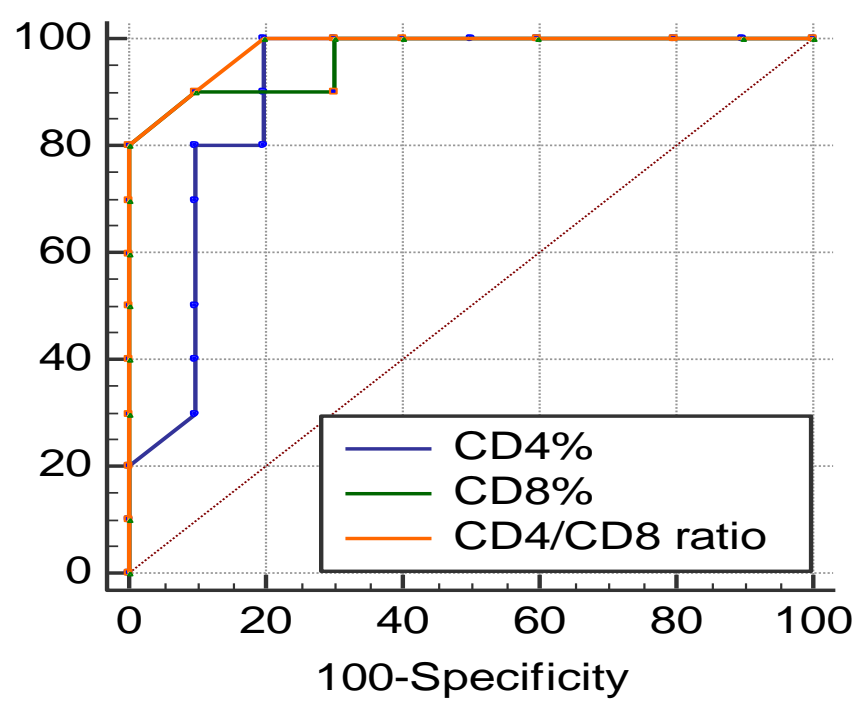

Figure (2): Receiver operating characteristic curve illustrating sensitivity, specificity, and area under the curve for discriminating moderate burns aged less than 3 days by CD $4+\%$, $\mathrm{CD} 8+\%$, and $\mathrm{CD} 4+/ \mathrm{CD} 8+$ ratio. 


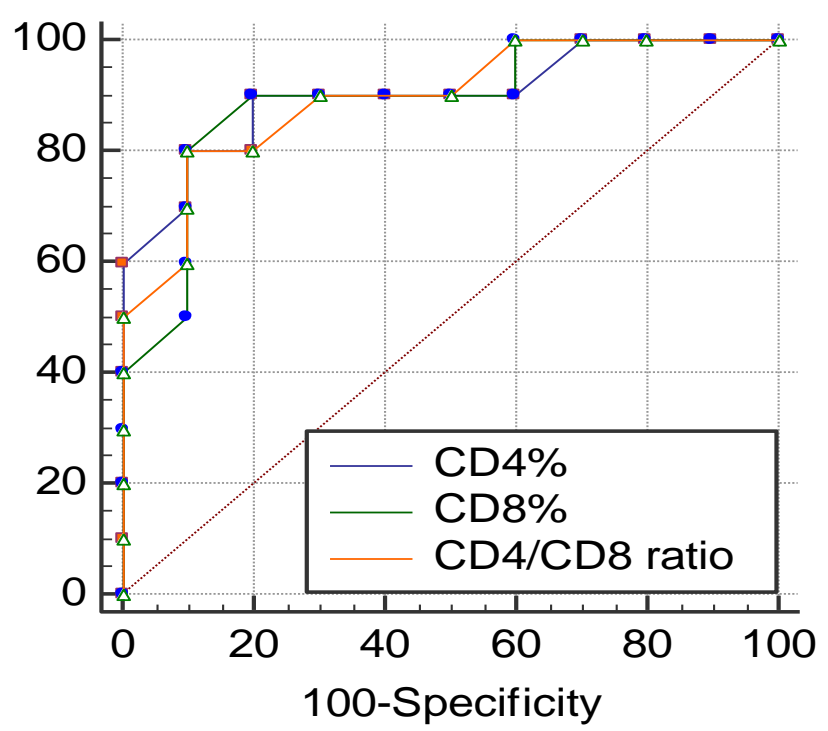

Figure (3): Receiver operating characteristic curve illustrating sensitivity, specificity, and area under the curve for discriminating severe burns aged less than 3 days by CD $4+\%$, $\mathrm{CD} 8+\%$, and $\mathrm{CD} 4+/ \mathrm{CD} 8+$ ratio.

Moreover, ROC curve analysis revealed that $\mathrm{CD} 4+, \mathrm{CD} 8+$ percentages and $\mathrm{CD} 4+/ \mathrm{CD} 8+$ ratio showed a significant- excellent power of discrimination of burns aged less than 3 days whatever the extent of the burn injury.

In the current study, significant timedependent immunosuppression of CD4+ and CD8+ T-cells in burnt patients along the first week was detected. Furthermore, CD4+ and CD8+ cells were declined as early as the 1st-day after-burn. Afterward, they were progressively suppressed with a remarkable decline on the 3rd day. The 7th day on the other hand showed partial restoration of the studied T-cell subtypes activity. Further gradual improvement of immunosuppression was continued with non-significant differences from the control on the 15th-day after-burn. In agreement with these findings, Haggag et al. (2013) have reported decreased expression of CD4+ and CD8+ $\mathrm{T}$ lymphocytes in the skin of moderate to severely burnt patients compared with healthy skin at 3 days and 1-week afterburn. Similarly, Sayed et al. (2012) have investigated T-lymphocyte subsets by flow cytometry in 50 patients with acute second-and third-degree major burns ranging from 25 to $40 \%$ of TBSA. They have recorded a statistically significant reduction in $\mathrm{CD}+4 / \mathrm{CD}+8$ ratio as early as the first 24 hours in comparison with healthy controls. Two weeks later, the $\mathrm{CD}+4 / \mathrm{CD}+8$ ratio was more or less similar to controls due to the activation of $\mathrm{T}$ lymphocytes at this time. Likewise, an earlier study has conveyed a significant decrease in absolute numbers of $\mathrm{CD}+4$ and CD8+ T-cells in patients with burn injury on the 4th-day after-burn compared with their controls (Mabrouk et al., 1997). Therapeutic implications of these findings have been previously reported where, triage of patients with major burns necessitates early and efficient support of their immune system to ensure better outcomes (Rafla and Tredget, 2011).

Our work revealed also a parallel decline in each of the CD4+ and CD8+ cells in the blood over time after burn injury. Thus, the two types of T-cells showed similar responses to burn injury. This coincided with Entezami and Mosavi (2017) who revealed a significant decline in CD4+ and CD8+ percentages and $\mathrm{CD} 4+/ \mathrm{CD} 8+$ ratio below the normal range at days 3 and 7 after burning by using flow cytometry. Conversely, it has been reported that $\mathrm{CD} 4+$ lymphocytes 
were mainly affected while, CD8+ count was not always reduced following thermal injury (Patenaude et al., 2005).

In this study, the observed CD4+ and CD8+ cells suppression was related to the extent of burns that was evaluated by the affected TBSA. Greater suppression was significantly observed in severe burns (>30-50\% TBSA) than moderate $(>10$ $30 \%$ TBSA) ones along the first-week after-burn. The impact of burn size on the amount of immunosuppression was also demonstrated by Jeschke et al. (2008). Another study showed an evident reduction in the ratio of $\mathrm{CD} 4$ to $\mathrm{CD} 8$ positive cells in patients with burns of more than $70 \%$ TBSA (Entezami and Mosavi, 2017). A remarkable early depression of $\mathrm{CD}+8$ T-cells in burnt patients in a size-dependent manner has also been recorded (Hultman et al., 1995). Likewise, Haggag et al. (2013) have reported a significant reduction in CD4+ and CD8+ counts in severe and extremely severe burns than moderate ones.

In this work, CD4+ and CD8+ T-cells suppression was recovered one week after moderate burns compared to 2 weeks after severe ones. This is in agreement with Devine et al. (2018) who reported recovery of $\mathrm{T}$-cells suppression in survivors after 2 weeks of burn injury. However, in patients with severe burn injuries that covered a greater body surface area, or in expired patients, this inflammatory cell influx persisted longer.

The detected alterations in CD4+ and CD8+ T-cells in the present study are likely to be multifactorial. Release of some suppressive substances from the burned tissue into the circulation resulting in inhibition of T-lymphocytes proliferation has been implicated (Church et al., 2006). In addition, immunosuppression might also be related to the burn-induced inflammatory response that starts immediately after the injury (Lateef et al., 2019). The production of several inflammatory cytokines and growth factors such as IL-1, tumor necrosis factor-alpha (TNF- $\alpha$ ), IL-6, IL-8, IL-10, tumor growth factor-beta (TGF- $\beta$ ), and interferon during the inflammatory response are potential mechanisms involved in the suppression of lymphocyte proliferation (Kim et al., 2012). Some of these cytokines (Valvis et al., 2015) and TNF- $\alpha$ (Yu et al., 2018) was identified as having a specific role in CD4+ or CD8+ T-cell homeostasis. Moreover, it has been found that plasma cytokines and TNF- $\alpha$ levels were related to burn size and time passed since thermal injury (Kim et al., 2012; Abdallah et al., 2019). Some have linked T-cells depletion after burn injury to the observed apoptosis of T-cells in the peripheral immune organs like the spleen and thymus (Girardot et al., 2017) while, others have shown that the reduced T-cells percentage in the blood resulting from their migration at the burn site and the nearby draining lymph nodes (Purcell et al., 2006; Rani et al., 2015; Rani and Schwacha, 2017).

Studying time-dependent changes at which mediators of the healing process are present in a group of burns of known age could assist in dating burns for forensic purposes (Schwacha et al., 2010). Despite extensive research in dating injury, no reliable gold standard marker has been achieved (van de Goot et al., 2014). The reason is that injury dating is a process that requires the incorporation of information collected from history taking, description of the situation, in addition to macroscopic and microscopic examination. Advanced techniques like immunohistochemistry or molecular biology are very helpful as well. They might add more information or help in solving discrepancies between some findings. Thus, the application of such techniques assists in making solid conclusions and valid statements (van de Goot and Fronczek, 2017). Considering this concept, the present study evaluated the diagnostic performance of $\mathrm{CD} 4+$, $\mathrm{CD} 8+\mathrm{T}$ percentages, and CD4+/CD8+ ratio in discriminating age of burns. Given the detected significant time-dependent 
differences of these markers in the univariate statistical analysis, the practical necessity for dating recent burns, and the small sample size, we aimed to detect the power of discriminating burns aged less than three days using the studied markers. The percentages of CD4+, CD8+ cells and CD4+/CD8+ ratio showed significantexcellent diagnostic value whatever the extent of burn injury.

The strengths of this study include investigating samples from living human subjects that have advantages of being of human origin besides the accuracy of their time data. Additionally, detecting CD4+ and CD8+ responses early after burns, and the presence of a less heterogeneous group of burnt patients at each studied time point may have produced more clear-cut results. However, a small sample size remains a limitation of this work.

\section{CONCLUSION \& RECOMMENDATION}

From these findings, it could be concluded that $\mathrm{CD}+4$ and $\mathrm{CD}+8 \mathrm{~T}$-cells in the blood exhibited time-dependent changes after dry burns. Additionally, they could help in determining the age of acute burns in human patients with great accuracy, whatever the extent of dry burn injury. Further research in patients with repeated burns and those with combined burns and trauma is recommended.

\section{REFERENCES}

Abdallah, E.A.; Ibrahim, N.A. and Kandeel, N.A. (2019): Age estimation for scald injury and its probable relation to testicular function impairment. The Egyptian Journal of Forensic Sciences and Applied Toxicology, 19(2): 87-100.

Cairns, B.A.; Maile, R.; Buchanan, I.; Pilati, D.; DeSerres, S.; Collins, E.J.; et al. (2001): $\mathrm{CD} 8(+) \mathrm{T}$ cells express a T-helper 1-like phenotype after burn injury. Surgery, 130(2): 210-216.

Church, D.; Elsayed, S.; Reid, O.; Winston, B. and Lindsay, R. (2006):
Burn wound infections. Clinical Microbiology Reviews, 19(2): 403434.

Cossarizza, A.; Chang, H.D.; Radbruch, A.; Akdis, M.; Andra, I.; Annunziato, F.; et al. (2017): Guidelines for the use of flow cytometry and cell sorting in immunological studies. European Journal of Immunology, 47(10): 15841797.

Devine, R.A.; Diltz, Z.; Hall, M.W. and Thakkar, R.K. (2018): The systemic immune response to pediatric thermal injury. International journal of burns and trauma, 8(1): 6-16.

El-Sayed, Y. S. (2016): Time course of histomorphologic features during chronic burn wound healing. Forensic Medicine and Anatomy Research, 4: 1-6.

Entezami, K. Z. and Mosavi, T. (2017): Determination of lymphocytes surface markers in patients with thermal burns and the influence of burn size on mononuclear cell subsets. Medical Journal of the Islamic Republic of Iran, 31: 38 .

Fronczek, J.; Lulf, R.; Korkmaz, H.I.; Witte, B.I.; van de Goot, F.R.; Begieneman, M.P.; et al. (2015): Analysis of inflammatory cells and mediators in skin wound biopsies to determine wound age in living subjects in forensic medicine. Forensic Science International, 247: 7-13.

Girardot, T.; Rimmele, T.; Venet, F. and Monneret, G. (2017): Apoptosisinduced lymphopenia in sepsis and other severe injuries. Apoptosis, 22(2): 295-305.

Greenbaum, A.R.; Horton, J.B.; Williams, C.J.; Shah, M. and Dunn, K.W. (2006): Burn injuries inflicted on children or the elderly: a framework for clinical and forensic assessment. Plastic and Reconstructive Surgery, 118(2): 46e-58e.

Haggag, O.G.; Fouda, A.A.; Eldin, A.A.S.; Al-Aziz, T.A.A. and 


\section{Mahmoud,}

A.A.

(2013):

Biochemical, histopathological and immunohistochemical study of burn lesions in patients admitted to Benha Educational Hospital: A prospective study (2009-2010). The Egyptian Journal of Forensic Science and Applied Toxicology, 13(2): 83-106.

Hultman, C.S.; Cairns, B.A.; deSerres, S.; Frelinger, J.A. and Meyer, A.A. (1995): Early, complete burn wound excision partially restores cytotoxic $\mathrm{T}$ lymphocyte function. Surgery, 118(2), 421-430.

Jeschke, M.G.; Chinkes, D.L.; Finnerty, C.C.; Kulp, G.; Suman, O.E.; Norbury, W.B.; et al. (2008): Pathophysiologic response to severe burn injury. Annals of Surgery, 248(3): 387-401.

Kim, A.; Lang, T.; Xue, M.; Wijewardana, A.; Jackson, C. and Vandervord, J. (2017): The Role of Th-17 Cells and $\gamma \delta$ T-Cells in modulating the systemic inflammatory response to severe burn injury. International Journal of Molecular Sciences, 18(4): 758.

Kim, H.S.; Kim, J.H.; Yim, H. and Kim, D. (2012): Changes in the levels of interleukins 6, 8, and 10, tumor necrosis factor alpha, and granulocytecolony stimulating factor in Korean burn patients: relation to burn size and postburn time. Annals of Laboratory Medicine, 32(5): 339-344.

Lateef, Z.; Stuart, G.; Jones, N.; Mercer, A.; Fleming, S. and Wise, L. (2019): The cutaneous inflammatory response to thermal burn injury in a murine model. International journal of molecular sciences, 20(3): 538.

Li, H.; Yao, Z.; Tan, J.; Zhou, J.; Li, Y.; Wu, J.; et al. (2017): Epidemiology and outcome analysis of 6325 burn patients: a five-year retrospective study in a major burn center in Southwest China. Scientific Reports, 7: 46066.
Li, N.; Du, Q.; Bai, R. and Sun, J. (2020): Vitality and wound-age estimation in forensic pathology: review and future prospects. Forensic Sciences Research, 5: 15-24.

Mabrouk, A.; Mabrouk, R.R.; Sabry, M. and Fedawy, S.F. (1997): Interleukin-6, CD4, and CD8 subsets of T-Lymphocytes in population of Egyptian Burn Patient. Annals of burns and fire disasters, 10(2): 85-89.

Mukherjee, R.; Tewary, S. and Routray, A. (2017): Diagnostic and prognostic utility of non-invasive multimodal imaging in chronic wound monitoring: a systematic review. Journal of Medical Systems, 41(3): 46.

Nisavic, M.; Nejad, S.H. and Beach, S.R. (2017): Intentional self-inflicted burn injuries: review of the literature. Psychosomatics, 58(6): 581-591.

Patenaude, J.; D'Elia, M.; Hamelin, C.; Garrel, D. and Bernier, J. (2005): Burn injury induces a change in $\mathrm{T}$ cell homeostasis affecting preferentially CD4+ T cells. Journal of Leukocyte Biology, 77(2): 141-150.

Purcell, E.M.; Dolan, S.M.; Kriynovich, S.; Mannick, J.A. and Lederer, J.A. (2006): Burn injury induces an early activation response by lymph node CD4+ T cells. Shock, 25(2): 135-140.

Rafla, K. and Tredget, E.E. (2011): Infection control in the burn unit. Burns, 37(1): 5-15.

Rani, M., and Schwacha, M.G. (2017): The composition of T-cell subsets are altered in the burn wound early after injury. PloS One, 12(6): e0179015.

Rani, M.; Zhang, Q.; Scherer, M.R.; Cap, A.P. and Schwacha, M.G. (2015): Activated skin $\gamma \delta$ T-cells regulate $\mathrm{T}$-cell infiltration of the wound site after burn. Innate Immunity, 21(2): 140-150.

Sayed, S.; Bakry, R.; El-Shazly, M.; ElOteify, M.; Terzaki, S. and Fekry, M. (2012): Effect of major burns on early and late activating markers of peripheral blood $\mathrm{T}$ lymphocytes. 
Annals of burns and fire disasters, 25(1): 17-21.

Schwacha, M.G., Thobe, B.M., Daniel, T. and Hubbard, W.J. (2010): Impact of thermal injury on wound infiltration and the dermal inflammatory response. Journal of Surgical Research, 158(1): 112-120.

Sorg, H.; Tilkorn, D.J.; Hager, S.; Hauser, J. and Mirastschijski, U. (2017): Skin wound healing: An update on the current knowledge and concepts. European Surgical Research, 58(1-2): 81-94.

Tarran, S.; Dziewulski, P.; Sztynda, T. and Langlois, N.E. (2004): A study of p53 expression in thermal burns of human skin for determination of wound age. Medicine, Science and the Law, 44(3): 222-226.

Tarran, S.; Langlois, N.E.; Dziewulski, P. and Sztynda, T. (2006): Using the inflammatory cell infiltrate to estimate the age of human burn wounds: A review and immunohistochemical study. Medicine, Science and the Law, 46(2): 115-126.

Valvis, S.M.; Waithman, J.; Wood,
F.M.; Fear, M.W. and Fear, V.S. (2015): The immune response to skin trauma is dependent on the etiology of injury in a mouse model of burn and excision. Journal of Investigative Dermatology, 135(8): 2119-2128.

van de Goot, F.R. and Fronczek, J. (2017): The dating of Injury; The five step approach. A clinical method to Enlighten forensic aspects. In: Essentials of Autopsy Practice. Springer, Cham; 157-177.

van de Goot, F.R.; Korkmaz, H.I.; Fronczek, J.; Witte, B.I.; Visser, R.; Ulrich, M.M.; et al. (2014): A new method to determine wound age in early vital skin injuries: a probability scoring system using expression levels of Fibronectin, CD62p and Factor VIII in wound hemorrhage. Forensic Science International, 244: 128-135.

Yu, B.; Xu, L.; Cai, M.; Zhang, D. and Li, S. (2018): Effect of tumor necrosis factor-alpha-induced protein 8 on the immune response of $\mathrm{CD} 4+\mathrm{T}$ lymphocytes in mice following acute insult. Molecular Medicine Reports, 17(5): 6655-6660. 


\section{الملخص العربي \\ تحديد عمر إصابات الحروق الجافة في مرضى الحروق عن طريث قياس التدفق الخلوي

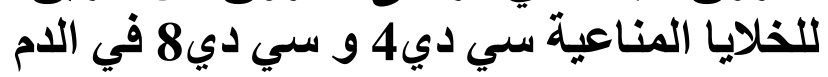

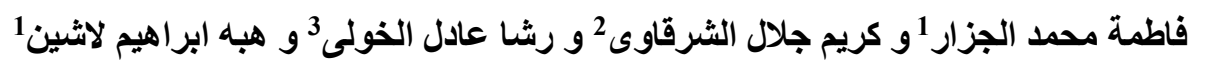

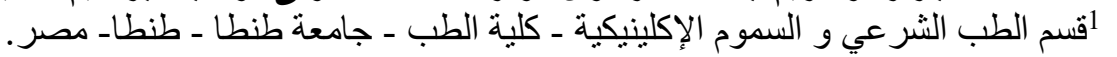

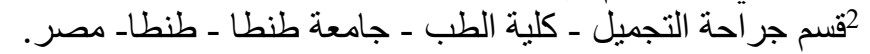

3قنم الباتولوجيا الإكلينيكية ـ كلية الطب - جامعة - جنة طنطا ـ طنطا- مصر.

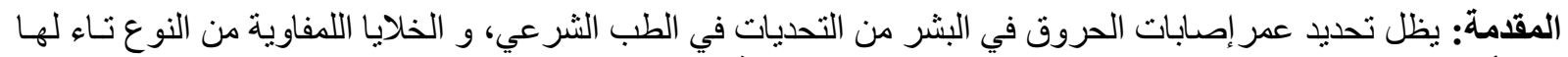

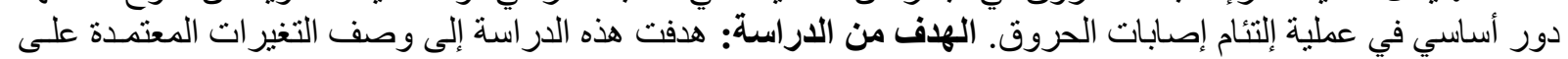

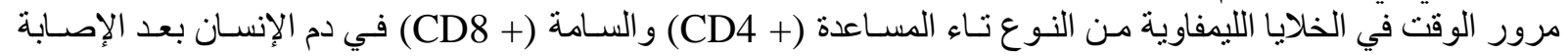

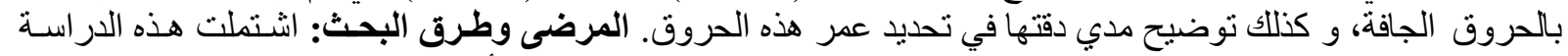

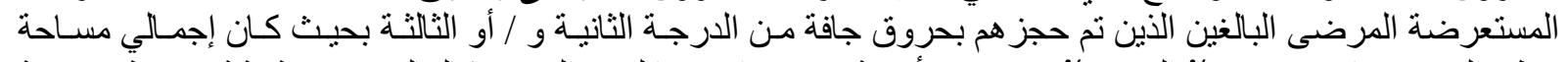

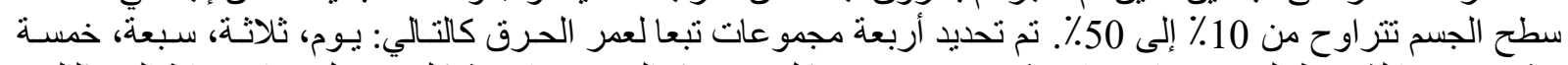

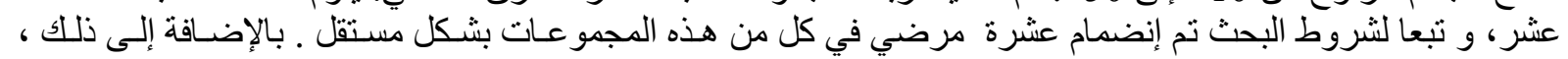

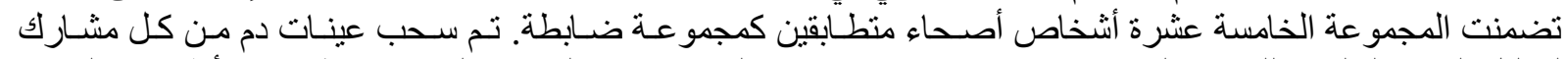

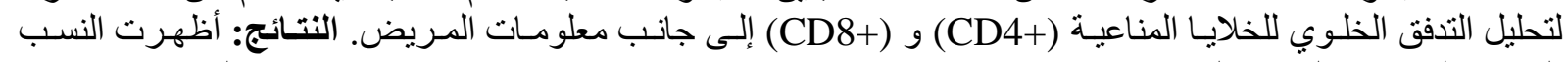

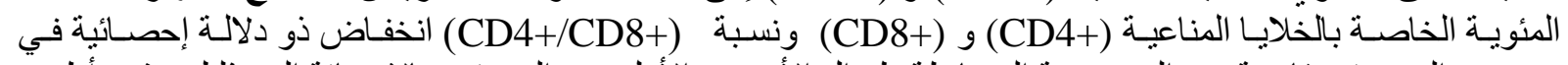

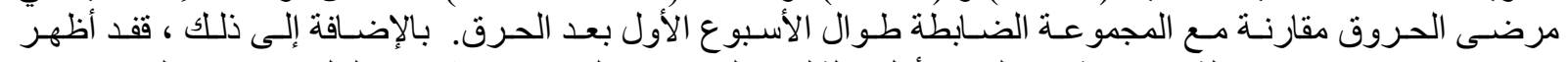

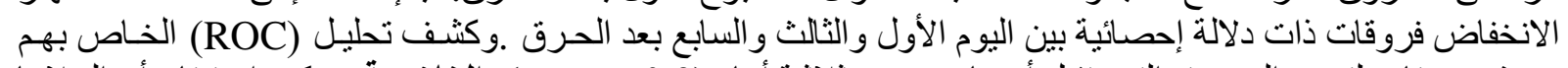

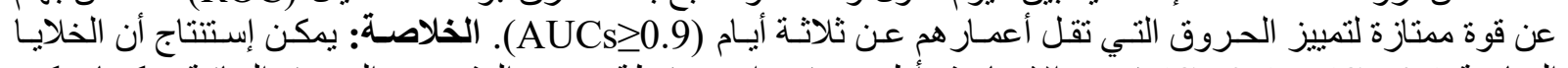

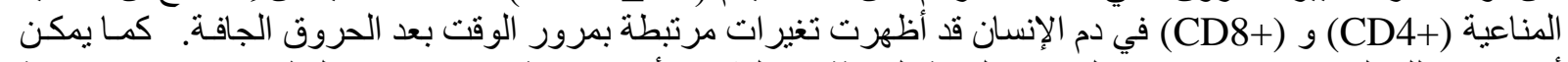

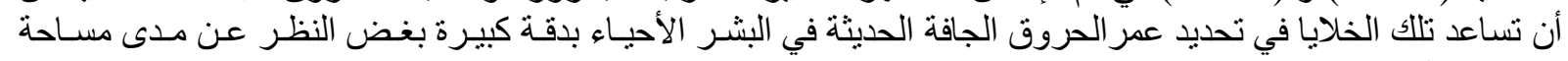
الإصابة بالحروق. 